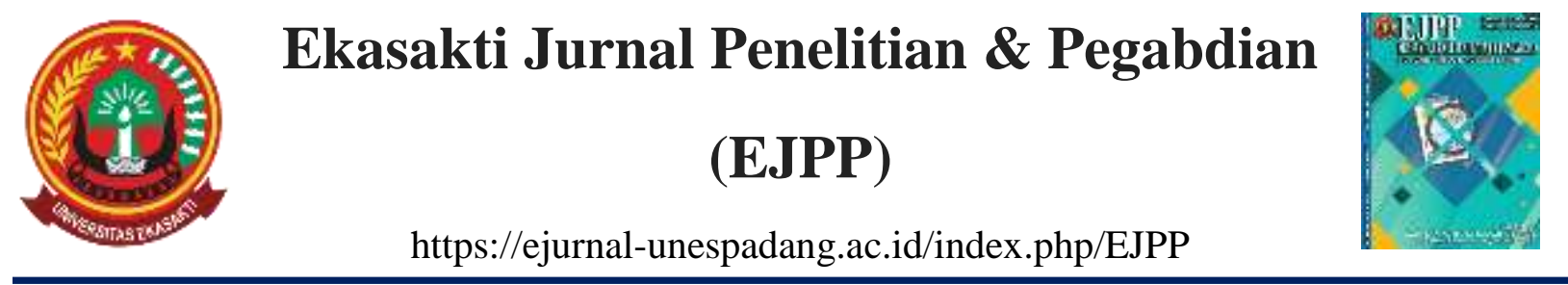

\title{
SIMULASI PENYEARAH TIGA FASA DENGAN MINIMUM TOTAL HARMONIC DISTORTION DENGAN METODE KONTROL ARUS RAMP COMPARISON CURRENT CONTROL PADA SISTEM TENAGA LISTRIK TIGA FASA
}

\author{
Hazlif Nazif ${ }^{1}$ \\ 1) Jurusan Teknik Elektro, Fakultas Teknik, Universitas Ekasakti Padang \\ Email: hazlif_n@yahoo.co.id
}

\section{INFO ARTIKEL}

Received : 14/02/2021

Revised : 30/02/2021

Publish : 01/05/2021

Kata Kunci:

Penyearah Tiga Phase, PSIM, THD, Kontrol Arus

Ramp Comparison

Current Control.

\begin{abstract}
ABSTRAK
Penyerah tiga phase adalah alat yang digunakan untuk mengubah tegangan AC menjadi tegangan DC. Penyearah jembatan tiga phase mengunakan dioda merupakan peralatan non linear tiga phase yang banyak dipergunakan dalam rumah tangga dan industri/pabrik. Namun Peralatan non linear tiga phase jenis ini menghasilkan arus harmonik pada jaringan listrik tiga phase sehingga mengalami kerusakan peralatan rumah tangga dan industri. Hal ini dapat diatasi adalah metode kontrol arus ramp comparison current control, diharapkan dapat mengurangi arus harmonik pada jaringan listrik tiga phase. Dalam penelitian ini, kontrol arus ramp comparison current control dibuat untuk penyearah tiga fasa terkendali mengunakan MOSFET untuk meninimalkan arus harmonisa pada sistem tenaga listrik tiga phase. Dilakukan melalui langkah-langkah penelitian ini yaitu perancangan dan pembuatan model dan simulasi dengan menggunakan perangkat lunak PSIM, kemudian pengujian dan analisa terhadap simulasi kontrol arus ramp comparison current control dengan melihat hasil pengujian dengan perangkat lunak PSIM. Dari hasil pengujian yang telah dilakukan, untuk frekuensi gelombang segitiga sebesar $20 \mathrm{kHz}$ pada amplitudo tetap 5V, diperoleh THD arus sebesar 5.2\%, hal ini berarti kualitas arus yang dihasilkan baik (rendah distorsi). Sedangkan untuk amplitudo gelombang sebesar 5 Volt pada frekwensi gelombang $20 \mathrm{kHz}$, THD arus yang dihasilkan adalah sebesar 5.2\%, sementara untuk amplitudo sebesar 9 Volt, THD arus yang dihasilkan adalah sebesar $8.4 \%$, hal ini berarti semakin tinggi amplitudo gelombang segitiga semakin buruk kualitas daya arus output yang diperoleh.
\end{abstract}

Keywords:

Three Phase Rectifier, PSIM, THD, Ramp

Comparison Current Control.

\section{ABSTRACT}

A three-phase rectifier is a device used to convert AC voltage into DC voltage. Three-phase bridge rectifier using a diode is a three-phase non-linear device that is widely used in households and industries / factories. However, this type of three-phase non-linear equipment produces harmonic currents in the threephase electrical network so that it experiences damage to household and industrial equipment. This can be overcome by the ramp comparison current control method, which is expected to reduce harmonic currents in the three- 
phase power grid. In this research, ramp comparison current control is made for controlled three-phase rectifier using MOSFET to minimize harmonic currents in a three-phase electric power system. Performed through the steps of this research, namely designing and making models and simulations using PSIM software, then testing and analysis of the current control simulation ramp comparison current control by looking at the test results with PSIM software. From the test results that have been carried out, for a triangle wave frequency of $20 \mathrm{kHz}$ at a fixed amplitude of $5 \mathrm{~V}$, the THD of the current is $5.2 \%$, this means that the resulting current is good (low distortion). Whereas for a wave amplitude of 5 volts at a wave frequency of $20 \mathrm{kHz}$, the resulting current THD is $5.2 \%$, while for an amplitude of 9 volts, the resulting current THD is $8.4 \%$, this means that the higher the amplitude of the triangle wave the worse the current power quality the output obtained.

DOI: https://doi.org/10.31933/ejpp.v1i2.252

\section{PENDAHULUAN}

Pemanfaatan peralatan elektronik tiga phase yang dipergunakan semakin meningkat dengan penyearah/rectifier tiga phase mengunakan dioda. Tujuan Penyearah ini adalah untuk mengubah tegangan bolak balik AC menjadi tegangan searah DC sesuai dengan kebutuhan peralatan yang bertegangan DC. Namun Penyearah ini menimbulkan harmonisa yang dapat mendistorsi gelombang fundamental sistem tenaga listrik sehingga mengalami kerusakan peralatan rumah tangga dan industri.

Untuk mengatasi permasalahan diatas maka diperlukan adalah kontrol arus ramp comparison current control, diharapkan dapat mengurangi kualitas arus yang buruk (tinggi distori) yang dihasilkan penyearah tiga fasa dioda pada sistem tenaga listrik tiga phase.

Pada penelitian ini, penulis mencoba membuat model dan simulasi kontrol arus ramp comparison current control untuk penyearah tiga fasa mengunakan MOSFET. Model dan simulasi dibuat dengan mengunakan software PSIM. Hal ini dikarenakan mempunyai respon dinamik yang sangat bagus dan frekuensi switching yang konstan. Kontrol arus ini mampu merespon perubahan pada sumber energi maupun grid dengan cepat dan harmonisa yang dihasilkan adalah dari jenis predictable harmonisa sehingga mudah diproteksi (B.Chitti Babu, 2010).

Oleh karena itu, penulis memandang perlunya dilakukan analisis terhadap penerapan kontrol arus ini pada penyearah tiga fasa mengunakan MOSFET. Hal ini diperlukan model yang mewakili penyearah tiga fasa sebenarnya sebagai obyek penelitian. Selain penyearah tiga fasa, diperlukan juga pengujiannya yang dapat menggambarkan mekanisme kerja sistem kontrol arus ini pada penyearah tiga fasa, agar penelitian menjadi lebih efisien.

Atas dasar itu, penulis bermaksud untuk membuat penelitian dengan judul " Simulasi Penyearah Tiga Fasa dengan Minimum Total Harmonic Distortion dengan Metode Kontrol Arus Ramp Comparison Current Control pada Sistem Tenaga Listrik Tiga Phase. Salah satu tujuan dilakukannya pengujiannya adalah untuk mengetahui kinerja strategi penyearah tiga phase dengan kontrol arus ramp comparison current control dengan melihat distori arus yang dihasilkan, yang diukur dengan parameter total harmonics distortion (THD). 


\section{METODE PENELITIAN}

\section{Model Penyearah Tiga Fasa dengan Kontrol Arus Ramp Comparison Current Control}

Sinyal arus referensi (Iref) ditambahkan dengan sinyal gelombang segitiga dengan sinyal arus sinusiodal dari sensor arus sehingga menghasilkan arus error, sinyal arus error dimasukkan ke dalam pengatur pulsa untuk membuat pola penyulutan komponen switch bagi rangkaian driver yang mengerakan saklar-saklar MOSFET pada penyearah 3 fasa terkendali, sehingga menghasilkan tegangan keluaran DC, sesuai dengan yang diperlukan peralatan bertegangan DC.

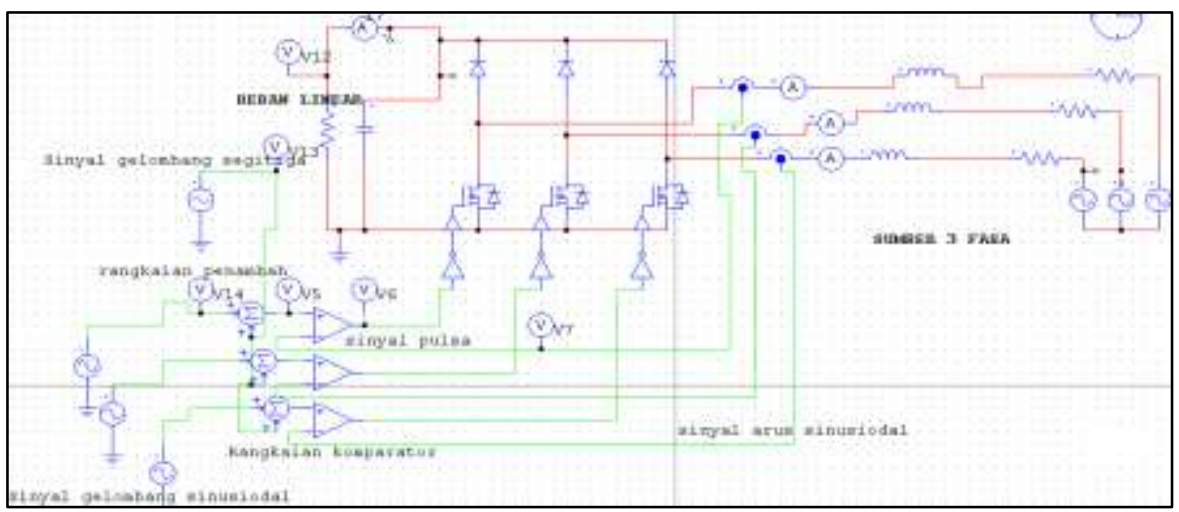

Gambar 1. Penyearah Tiga Fasa dengan Kontrol Arus Ramp Comparison Current Control

\section{Model Kontrol Arus Ramp Comparison Current Control}

Gambar 2 menunjukkan model simulasi kontrol arus ramp comparison current control. Input dari blok ini adalah sinyal referensi dari blok sinusiodal dan gelombang segi tiga dengan frekuensi tertentu. Sedangkan outputnya merupakan sinyal gate bagi komponen switch pada penyearah tiga fasa mengunakan MOSFET.

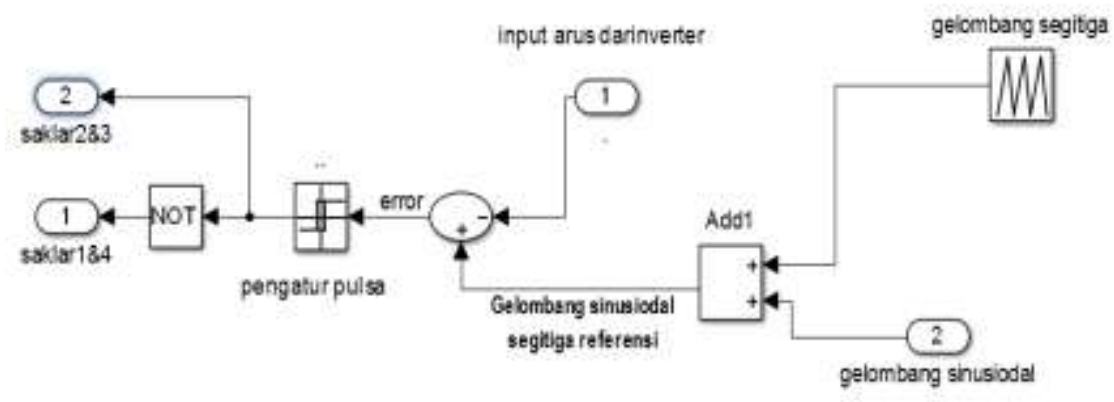

Gambar 2. Model Kontrol Arus Ramp Comparison Current Control 


\section{Model Penyearah 3 Fasa}

Gambar 3 menunjukkan simulasi secara lengkap yang digunakan dalam penelitian ini.

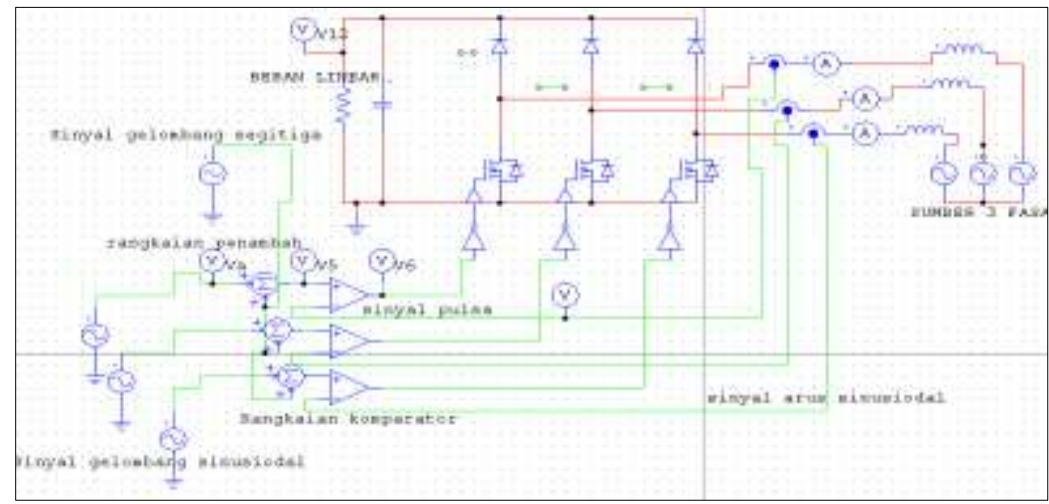

Gambar 3. Simulasi Kontrol Arus Ramp Comparison Current Control pada Penyearah 3 Fasa

\section{HASIL DAN PEMBAHASAN}

\section{Pengujian Kontrol Arus Ramp Comparison Current Control}

Untuk melihat gelombang keluaran dari kontrol arus ramp comparison current control, pengujian ini dilakukan dengan frekuensi gelombang segitiga diset $20 \mathrm{kHz}$ dan amplitudo sebesar 10volt diberi. Induktor $1 \mathrm{mH}$ dipasang pada jaringan listrik tiga fasa, sedangkan kapasitor 1000 $\mathrm{uF}$ dipasang pada penyearah terkendali tiga fasa terhubung dengan beban $200 \Omega$. Gambar 4 menunjukkan hasil pengujian kontrol arus ini.

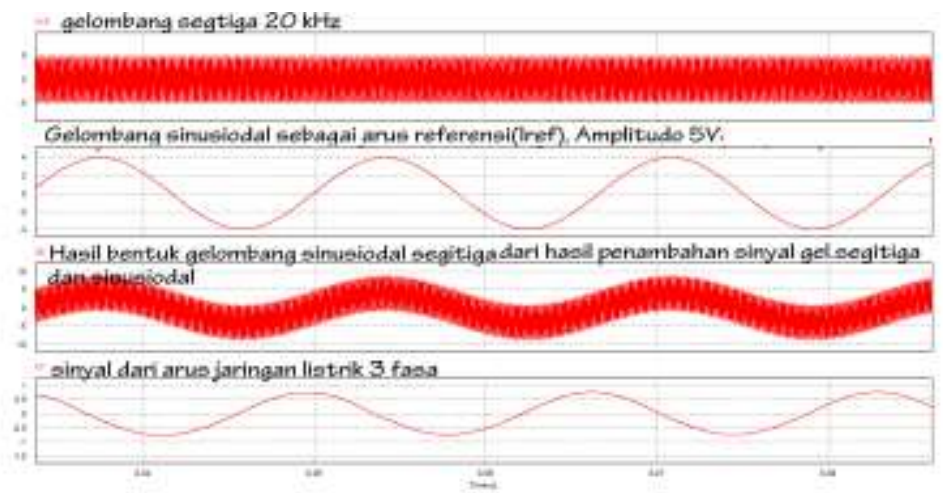

Gambar 4. Hasil simulasi Sinyal modulator PWM kontrol arus ramp

\section{Pengujian Penyearah Tiga Fasa dengan Kontrol Arus Ramp Comparison Current Control}

Untuk melihat tegangan dan arus keluaran DC dari penyearah tiga fasa, pengujian ini terhadap penyearah tiga fasa terhubung dengan beban linear $200 \mathrm{Ohm}$, yang dilakukan dengan 
nilai amplitudo 10 Volt dan frekuensi switch $20 \mathrm{kHz}$. Dari hasil simulasi ini, menunjukkan bahwa tegangan keluaran DC $300 \mathrm{~V}$ dan arus keluaran 1.5 A.

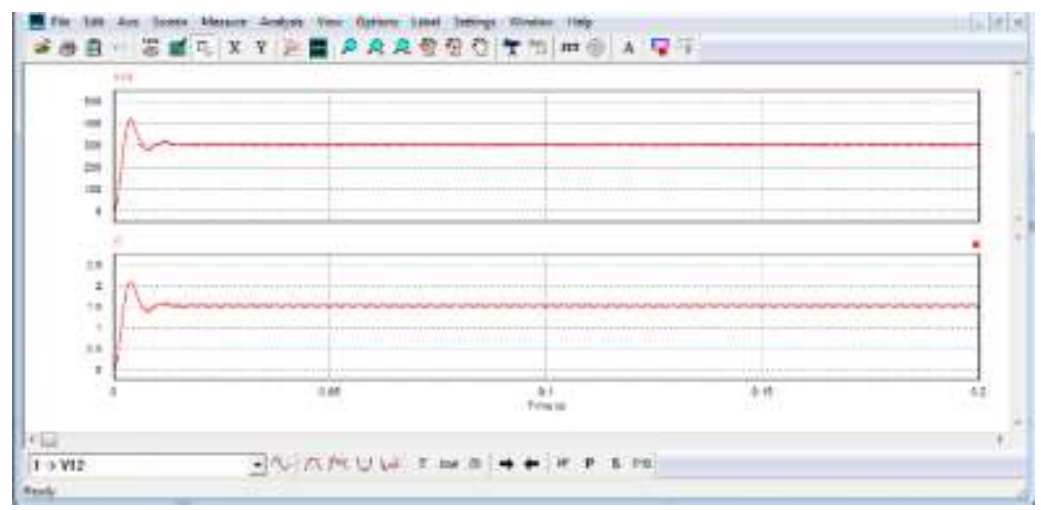

Gambar 5. Hasil simulasi menunjukkan tegangan keluaran DC $300 \mathrm{~V}$ dan arus keluaran $1.5 \mathrm{~A}$

\section{Arus Input pada Jaringan Listrik Tiga Fasa}

Untuk melihat bentuk gelombang arus input pada jaringan listrik tiga fasa, pengujian ini yang dilakukan pada jaringan tenagan listrik, dengan induktor $1 \mathrm{mH}$, tahanan $5 \mathrm{ohm}$ dan kapasitor 1000uF. Hasil simulasi ini menunjukkan pada gambar dibawah ini.

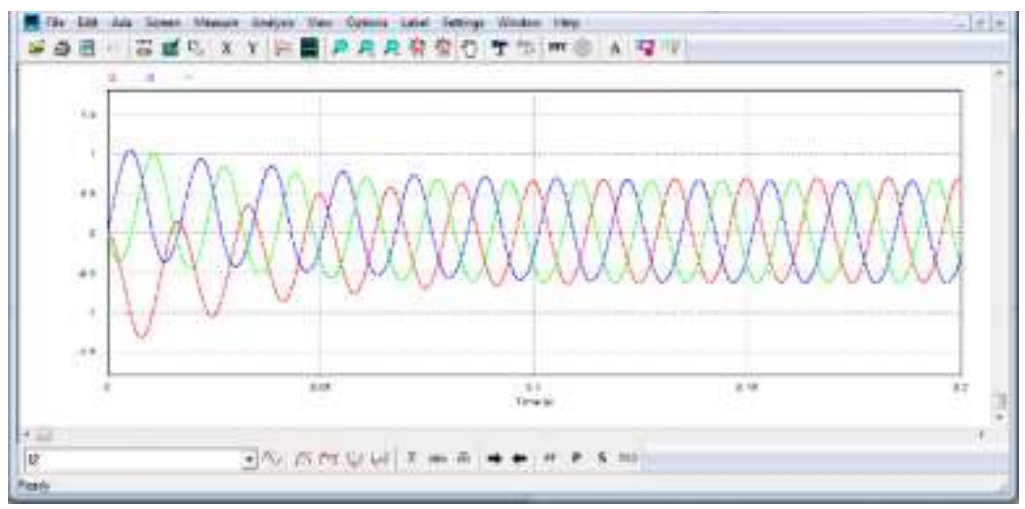

Gambar 6. Hasil Bentuk Gelombang Arus Input

\section{THD Arus input}

Untuk melihat THD arus input pada penyearah tiga fasa, pengujian ini dilakukan dengan memvariasikan frekuensi dan amplitudo gelombang segitiga. Dengan frekuensi switching bervariasi pada amplitudo tetap 10V. Hasil pengujian yang telah dilakukan maka diperoleh bahwa THD arus sebesar $3.7 \%$ (distori rendah), diperlihatkan pada tabel 1 .

Tabel 1. THD arus input dengan frekuensi divariasikan pada amplitude tetap 10 volt

\begin{tabular}{ccc}
\hline No & Frekuensi switching & THD \\
\hline 1 & $10 \mathrm{KHz}$ & $3.7 \%$ \\
2 & $12 \mathrm{KHz}$ & $3.7 \%$ \\
3 & $15 \mathrm{KHz}$ & $3.7 \%$ \\
\hline
\end{tabular}




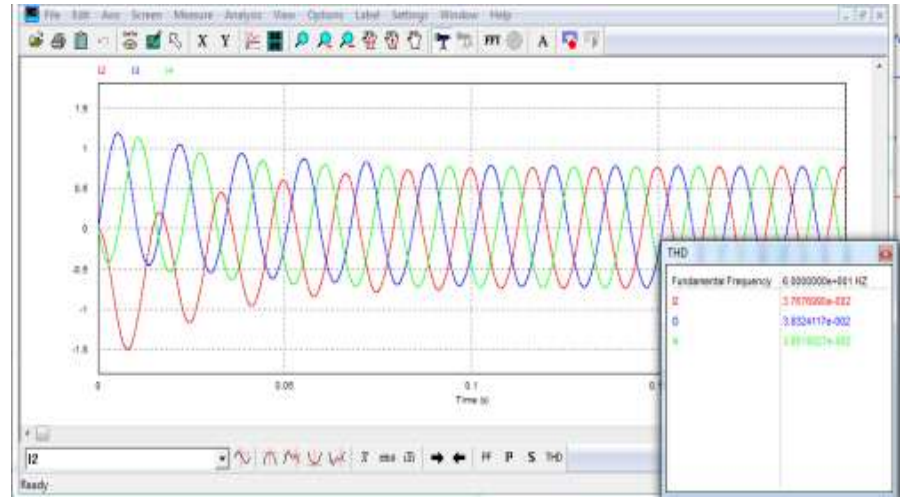

(a)

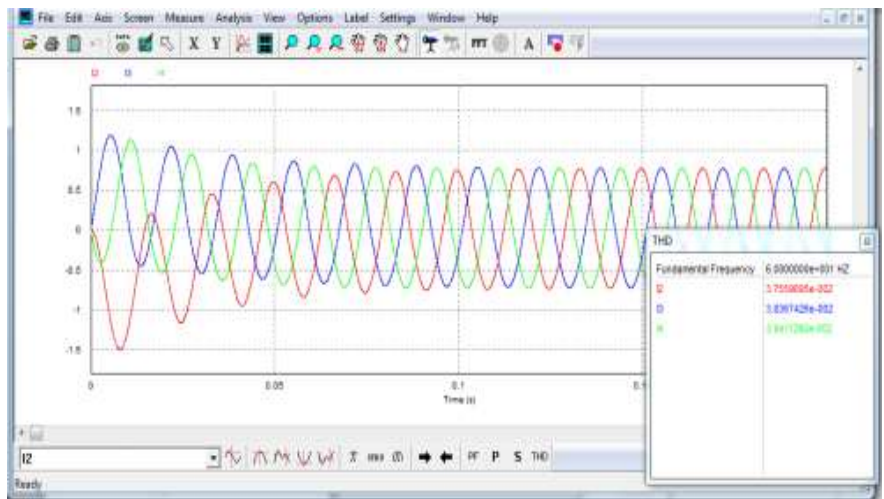

(b)

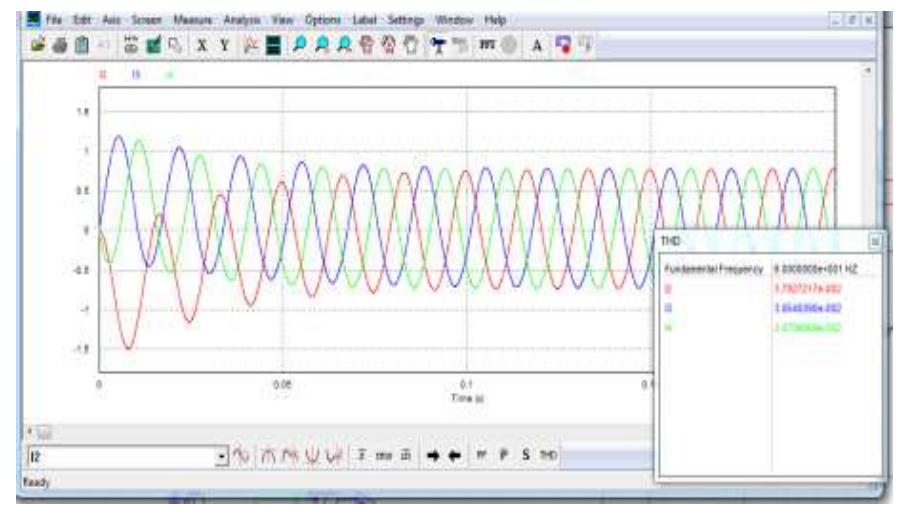

(c)

Gambar 7. Dengan fs bervariasi pada amplitudo 10 Volt tetap (a) THD 3.7\%, (b). THD 3.7\% dan (c). THD 3.7\%

Dengan amplitudo bervariasi pada frekuensi switching tetap 10V. Hasil pengujian yang telah dilakukan maka diperoleh bahwa semakin amplitudo tinggi kualitas THD semakin rendah (distori rendah), diperlihatkan pada tabel 2. 
Tabel 2. THD arus input dengan amplitudo divariasikan pada frekuensi switching gelombang segitiga tetap.

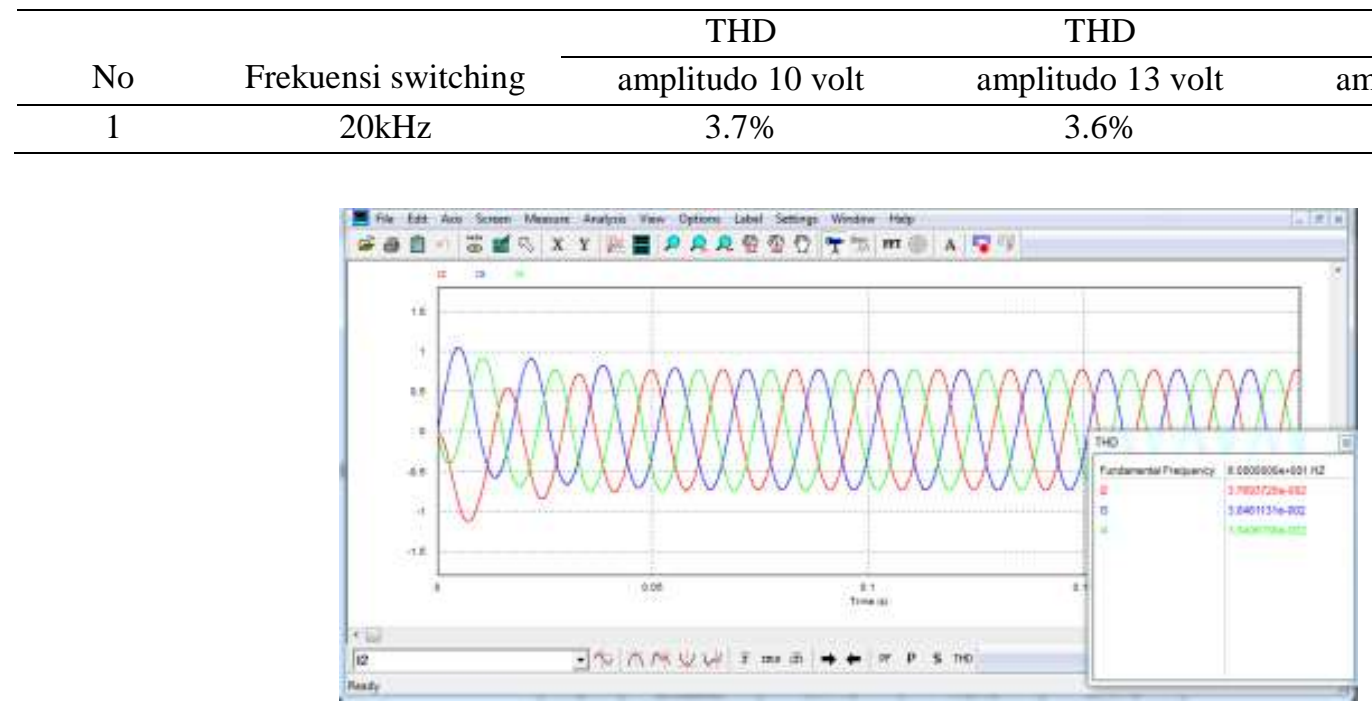

(a)

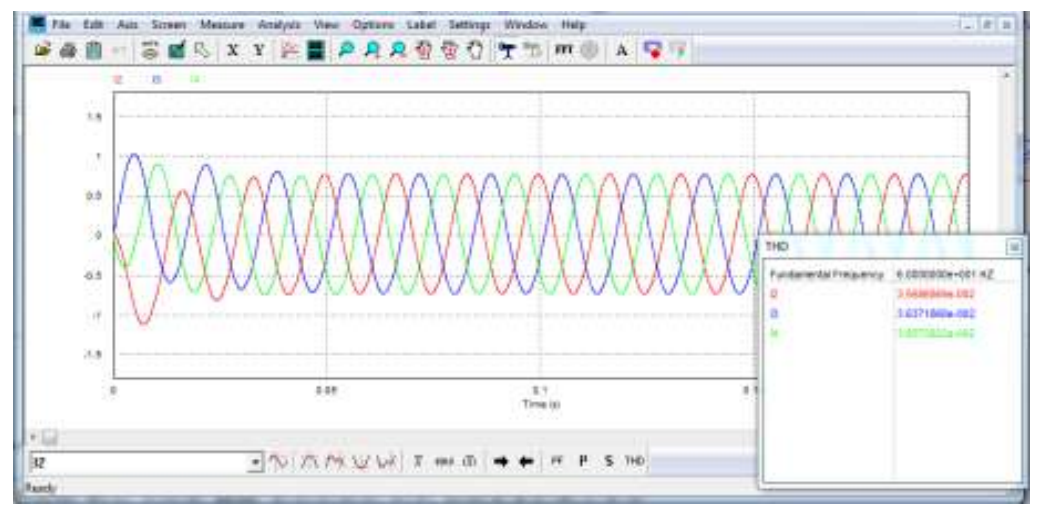

(b)

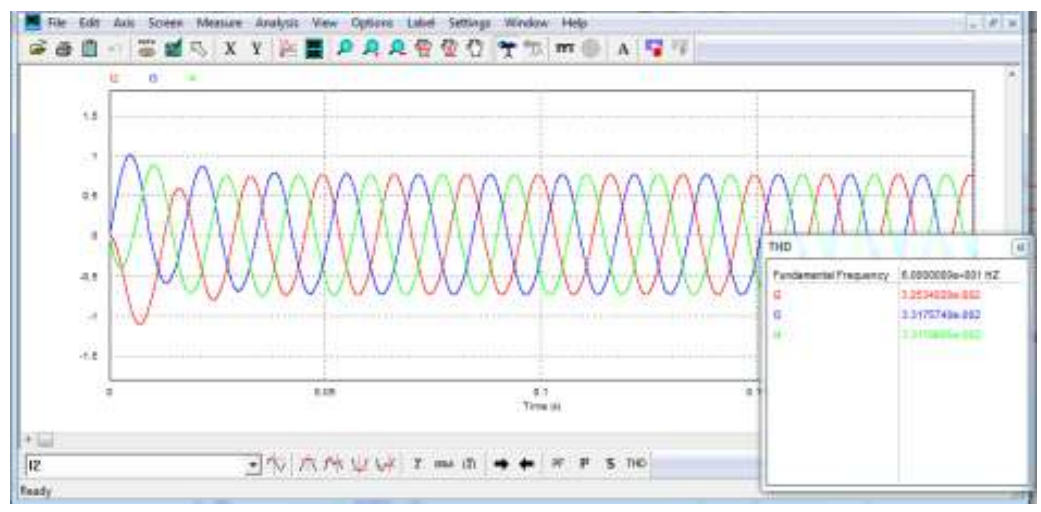

(c)

Gambar 8. Dengan amplitudo divariasikan pada fs tetap:

(a).THD $3.7 \%$,(b).THD $3.6 \%$ dan (c).THD 3.3\% 


\section{KESIMPULAN}

Dari hasil simulasi dan analisa kontrol arus ramp comparison current control pada penyearah satu fasa, dapat disimpulkan bahwa:

1. Pemodelan kontrol arus ini telah berhasil dibuat dengan software PSIM, sesuai dengan teori

2. Bahwa frekuensi gelombang segitiga $20 \mathrm{kHz}$ pada amplitudo $5 \mathrm{~V}$ tetap, maka kualitas arus yang dihasilkan baik (rendah distorsi). Sementara itu, pada frekuensi switching tetap, amplitudo gelombang segitiga semakin tinggi maka kualitas daya arus output yang diperoleh baik.

Simulasi ini digunakan untuk aplikasi simulasi praktikum/media pembelajaran praktikum khususnya pada mata kuliah eletronika daya.

\section{REFERENSI}

B.Chitti Babu, B.Vasantha Reddy and K.B.Mohanty(2010). A Novel Delta Modulator and Modified Ramp Type Current Controller-Two Viable Scheme for Current Controlled Voltage Source Inverter, International Journal of Computer Applications (0975 - 8887) Volume 1, No. 3.

Hari Anna Lastya (2017), Analisa Perancangan Filter LCL Pada Penyearah PWM Satu Fasa Full Bridge,CIRCUIT: Jurnal Ilmiah Pendidikan Teknik Elektro,Vol.1, No.2, Agustus 2017, hal.108-120 ISSN 2549-3698 (printed)/ 2549-3701 (online).

Janny F. Abidin (2015). Analisis Unjuk Kerja Harmonik di Instalasi Listrik Industri dan Upaya Penanggulanggannya, Jurnal Teknologi Elektro, Universitas Mercu Buana, Vol 6, No 3 ISSN: 2086-9479

Muh.Imran Hamid dan Makbul Anwari, (2010) Single-Phase Photovoltaic-Inverter operation characteristic in Distributed Generation System, http://www.intechopen.com/download/pdf/10142.

Hazlif Nazif, Susy Yuliastanty(2019), Rancang Bangun Kontrol Arus Ramp Comparsion Current Control untuk Penyearah Tiga Fasa pada Sistem Tenaga Listrik, Jurnal Teknik Elektro ITP, Vol. 8, No. 2. 